\title{
Global modelling of continental water storage changes - sensitivity to different climate data sets
}

\author{
K. Fiedler and P. Döll \\ Department of Physical Geography, University of Frankfurt, Germany \\ Received: 18 January 2007 - Revised: 13 April 2007 - Accepted: 15 May 2007 - Published: 11 June 2007
}

\begin{abstract}
Since 2002, the GRACE satellite mission provides estimates of the Earth's dynamic gravity field with unprecedented accuracy. Differences between monthly gravity fields contain a clear hydrological signal due to continental water storage changes. In order to evaluate GRACE results, the state-of-the-art WaterGAP Global Hydrological Model (WGHM) is applied to calculate terrestrial water storage changes on a global scale. WGHM is driven by different climate data sets to analyse especially the influence of different precipitation data on calculated water storage. The data sets used are the CRU TS 2.1 climate data set, the GPCC Full Data Product for precipitation and data from the ECMWF integrated forecast system. A simple approach for precipitation correction is introduced. WGHM results are then compared with GRACE data. The use of different precipitation data sets leads to considerable differences in computed water storage change for a large number of river basins. Comparing model results with GRACE observations shows a good spatial correlation and also a good agreement in phase. However, seasonal variations of water storage as derived from GRACE tend to be significantly larger than those computed by WGHM, regardless of which climate data set is used.
\end{abstract}

\section{Introduction}

Continental water storage makes up an essential part of the global hydrological cycle. It is of particular importance for the existence of many ecosystems and for the satisfaction of human demands, including water for agricultural, industrial and domestic use. Total continental water storage is considered as the sum of water stored as snow and ice, in and on vegetation covers, in the unsaturated soil zone, in groundwa-

Correspondence to: K. Fiedler

(fiedler@em.uni-frankfurt.de) ter and surface waters like rivers, wetlands, lakes and reservoirs. According to the terrestrial water balance equation

$P=R+E T R+\Delta S$

precipitation $(P)$ equals runoff $(R)$ plus evapotranspiration $(E T R)$ plus water storage change $(\Delta S)$. Little is known about the spatial and temporal variability of water storage on a global scale although this information is important for understanding the global water cycle. Direct estimations of $\Delta S$ are often restricted to the point scale and to single components of total water storage, such as groundwater or lakes (Rodell and Famiglietti, 2001, 2002). A determination of water storage change by solving Eq. (1) is practically impossible because even in basins with good precipitation and river discharge data, ETR cannot be measured reliably, except for very small basins. Another attempt to assess $\Delta S$ is the combined atmospheric - terrestrial water balance approach (Seneviratne, 2004; Hirschi et al., 2006a, b) in which atmospheric moisture flux and water content as computed by atmospheric circulation models and river discharge observations are required.

A new type of information about the spatial and temporal variations of continental water storage on a global scale is expected from the Gravity Recovery and Climate Experiment (GRACE) - a European-American satellite mission launched in 2002. Based on very exact measurements of the distance between two satellites orbiting the Earth in an altitude of about $500 \mathrm{~km}$, monthly solutions of the Earth's gravity field are modelled. The differences between monthly solutions contain a clear hydrological signal because changing volumes of water stored on or beneath the Earth's surface lead to small temporal variations of the Earth's gravity field. Changes of continental water storage are computed by subtracting mass variations of atmospheric, oceanic and other tidal contributions from the overall gravitational signal (Schmidt et al., 2006; Ramillien et al., 2004).

Published by Copernicus Publications on behalf of the European Geosciences Union. 
Due to the already mentioned lack of appropriate observation data on macro-scale water storage, GRACE mission results need to be evaluated by comparison with global hydrological models. In this study, water storage is calculated with the WaterGAP Global Hydrological Model (WGHM) which includes a state-of-the-art representation of water storage components. In order to compare GRACE data with results from WGHM, it is important to know the uncertainty of continental water storage change as computed by WGHM. Climate input is an important source of uncertainty. Therefore, the model is driven by different climate data sets to get a better understanding especially of the influence of precipitation data on calculated water storage change. In a first preliminary analysis, the different climate data sets and the corresponding model results are evaluated and compared with results from GRACE for some of the world's largest river basins.

\section{Methods}

Since 1996, the global hydrological model WaterGAP (Water - Global Analysis and Prognosis) has been developed at the Centre for Environmental Systems Research at the University of Kassel. Since 2003, further model development is done both in Kassel and at the University of Frankfurt. A detailed model description can be found in Döll et al. (2003). The conceptual approach of the model structure identifies total water storage as the sum of canopy, snow, soil and groundwater storage as well as water stored in surface water bodies like rivers, wetlands, lakes and reservoirs. Anthropogenic water use for irrigation, industrial and domestic purposes is also taken into account.

The previous WaterGAP 2.1e model version was driven by monthly climate data from the Climate Research Unit (CRU). The CRU TS 2.1 data set provides gridded data for several climate variables like precipitation, number of rain days, temperature and cloudiness from 1901-2002 with a spatial resolution of $0.5^{\circ}$ covering the global land surface. This dataset is based on station observations and was calculated using the statistical approach of anomaly analysis (see Mitchell et al., 2005 and New et al., 2000 for details).

For the recent WaterGAP 2.1f model version a different data set for precipitation is used additionally to estimate the uncertainty of computed water storage due to the uncertainty of precipitation input. We focussed on precipitation as it is well known that precipitation is the climate variable which most influences the continental part of the water cycle. The Global Precipitation Climatology Centre (GPCC) provides a gridded monthly precipitation product for the global land surface. This GPCC Version 3 Full Data Product is available from 1951-2004 with a spatial resolution of $0.5^{\circ}$ (Rudolf and Schneider, 2005). It is based on a larger number of station observations than the CRU data and covers the time period of the first GRACE results. For the year 2005, the so-called
Monitoring Product is used from GPCC, based on a smaller number of station observations and a less intensive data processing.

CRU and GPCC precipitation data are not corrected for measurement errors. Especially winter precipitation is often underestimated due to wind induced solid precipitation undercatch. As this is supposed to have a strong influence on snow water storage, a first simple approach for precipitation correction is tested. According to Legates and Willmott (1990), correction is based on the following equation:

$$
\begin{aligned}
P_{c}= & \kappa_{r} \times\left(P_{g}+\Delta P_{w r}+\Delta P_{e r}\right) \times(R-1) \\
& +\kappa_{s} \times\left(P_{g}+\Delta P_{w s}+\Delta P_{e s}\right) \times R
\end{aligned}
$$

$P_{c}$ is the corrected precipitation, $\kappa$ is a wind correction factor, $P_{g}$ is the measured gauge precipitation, $\Delta P_{w}$ is the wetting loss and $\Delta P_{e}$ the evaporative loss. The subscripts $r$ and $s$ are used for rain and snow, respectively, and $R$ indicates the proportion of precipitation that falls as snow. Adam and Lettenmaier (2003) created a global data set of gridded mean monthly catch ratios ( $\mathrm{CR}=$ gauge precipitation/adjusted precipitation) for the adjustment of wind induced undercatch and wetting losses, with a spatial resolution of $0.5^{\circ}$ suitable for the application to gridded precipitation products. This dataset contains mean monthly values for precipitation correction. In order to take actual monthly temperatures into account (e.g. to decrease correction factors in a warm winter), the proportion of snow $(R)$ as a function of temperature is introduced into the correction formula. In Legates and Willmott (1990), $R$ is estimated as

$R=\frac{1}{1+1,61 \times(1,35)^{T}}$

Here, $T$ is the mean monthly temperature. Using this relationship between snow percentage and temperature, a new algorithm for monthly precipitation correction is tested in WGHM based on the following equation:

$P_{c}=P_{g} \times\left[\frac{1}{C R} \times \frac{R(T)}{R(\overline{T)}}\right]$

with catch ratios $(C R)$ from Adam and Lettenmaier (2003), $T$ as the actual mean and $\bar{T}$ as the long term mean (1961-1990) monthly temperature.

As CRU climate parameters like temperature and cloudiness are only available until 2002 and GRACE results are obtained since 2003, another source for these climate variables has to be found to apply the model in recent years. For this purpose, results from the ECMWF operational forecast system are taken to get global gridded data for temperature, cloudiness and the number of rain days.

WGHM is calibrated by adjusting only one parameter. The runoff coefficient $\gamma$ determines the relationship between soil moisture and runoff - a modelling approach taken from the HBV hydrological model concept (Bergström, 1992). The parameter $\gamma$ is calibrated against discharge measurements 
Table 1. Comparison of calibration results based on CRU and GPCC precipitation data.

\begin{tabular}{llllc}
\hline Precipitation data set & \multicolumn{2}{c}{ CRU } & \multicolumn{2}{c}{ GPCC } \\
\hline & $\begin{array}{l}\text { Number of } \\
\text { discharge stations }\end{array}$ & Area [\%] & $\begin{array}{l}\text { Number of } \\
\text { discharge stations }\end{array}$ & Area [\%] \\
\hline acceptable $\gamma(0.3<\gamma<3)^{1}$ & 471 & 39.4 & 454 & 37.2 \\
$\gamma=0.3$ (underestimated discharge) & 480 & 34.6 & 506 & 36.7 \\
$\gamma=3.0$ (overestimated discharge) & 284 & 26.0 & 275 & 26.1 \\
AME $>0.5^{2}$ & 514 & 45.3 & 541 & 45.5 \\
MME $>0.5^{3}$ & 475 & 37.8 & 502 & 39.5 \\
\hline
\end{tabular}

$1 \gamma$ - runoff coefficient in WaterGAP, used as calibration parameter, predefined acceptable values between 0.3 and 3

2 AME - annual modelling efficiency

${ }^{3}$ MME - monthly modelling efficiency

at 1235 gauging stations worldwide so that the calculated long-term mean annual river discharge matches the observed values within a range of $1 \%$ deviation. Additional correction factors are applied when the calibrated parameter is outside a predefined accepted range. In areas outside calibration basins, the parameter $\gamma$ is regionalised according to physiographic characteristics (Döll et al., 2003). The whole calibration procedure is performed twice: 1 ) with the CRU climate dataset and 2) with GPCC precipitation data and other climate variables from CRU. The results of both calibration runs are analysed and compared.

Continental water storage change is calculated with WGHM for the largest river basins worldwide using different precipitation data. Model results are then compared with GRACE.

\section{Results}

\subsection{Comparison of CRU and GPCC precipitation data}

The CRU and GPCC precipitation data sets show great differences, e.g. in north-western Africa where the CRU precipitation data are generally smaller than the GPCC values (data not shown). The opposite behaviour can be identified e.g. in the north-eastern part of Africa like the lower Nile basin, as well as in the European Alps or Central Asia where the CRU values are higher than the GPCC values. Looking at the long-term mean (1961-1990), in only 39\% of all modelled cells the CRU and GPCC precipitation data show little differences $(+/-5 \%)$. The global long-term mean annual precipitation sums (averaged over all $0.5^{\circ}$ model cells) are $721 \mathrm{~mm}$ for CRU and $708 \mathrm{~mm}$ for GPCC data. GPCC mean precipitation tends to be smaller than CRU precipitation on a global scale, a fact already mentioned in other comparison studies (Österle et al., 2003). The above mentioned differences might be due to the different number of station observations used to create the gridded data product. Additionally, the algorithms for the spatial interpolation of point data and for data processing (e.g. handling of inhomogeneities, overlapping station records etc.) are different between the two data sources.

Precipitation correction of GPCC data using Eq. (4) leads to a global increase in yearly precipitation of $11.7 \%$ for 1961-1990. Especially in northern snow-dominated regions, an increase between original and corrected GPCC precipitation is achieved due to higher correction factors in winter months to account for solid precipitation undercatch.

\subsection{Comparison of calibration results}

The model calibration to discharge measurements at 1235 gauging stations is performed both for CRU and GPCC precipitation data. A comparison of calibration results is presented in Table 1. The annual and monthly modelling efficiency (AME and MME) are calculated following the formula of Nash and Sutcliffe (1970) for observed and modelled annual and monthly discharge values at the selected stations. As can be seen in Table 1, calibration with GPCC precipitation data leads to a decreasing number of stations where $\gamma$ can be adjusted within the predefined acceptable range of 0.3 and 3. Nevertheless, the number of stations with AME or MME greater than 0.5 increases, indicating a slight improvement of calibration.

\subsection{Calculation of water storage change}

Taking the results of both calibration runs and the different precipitation data into account, WGHM is used to calculate total water storage change ( $\Delta$ TWS) on a global scale. $\Delta \mathrm{TWS}_{\text {seasonal }}$ is computed as the intra-annual amplitude of storage change between months with maximum and minimum water storage within one year. For a first preliminary assessment, the year 2002 is selected.

As can be seen in Fig. 1, seasonal water storage change computed with WGHM shows large values in tropical 


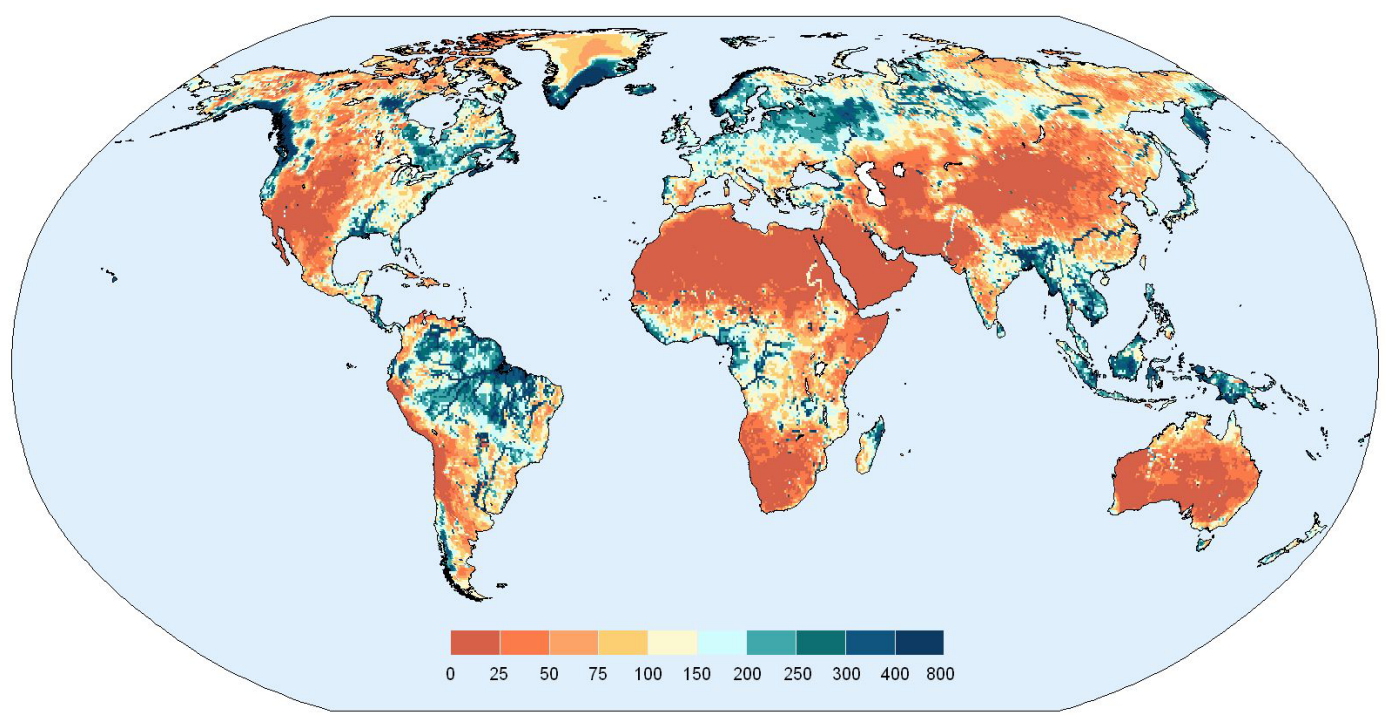

Fig. 1. Seasonal water storage change* $(\mathrm{mm})$ for the year 2002 - calculated with WGHM based on GPCC precipitation data. (* Seasonal water storage change $=$ the difference between maximum and minimum monthly storage within one year)

climate zones due to large intra-annual differences in precipitation (e.g. South-East Asia). In the Amazon basin, a strong storage change signal can also be identified due to the great varying volumes of water stored within surface water bodies. Furthermore, snow-dominated regions show remarkable seasonal variations in water storage due to the accumulation of water in terms of snow during winter months until the snow melt in spring or summer. In Fig. 1, linear features along major rivers can also be identified due to the high amount of discharge volume contributing locally to $\triangle$ TWS.

To compare the model output based on different precipitation data, the results are averaged for the world's largest river basins (basins with an area greater than $200000 \mathrm{~km}^{2}$ ). In Fig. 2, the difference between seasonal water storage change computed with CRU vs. GPCC precipitation data is calculated as the ratio of the two values, aggregated for large river basins. In $17 \%$ of all selected basins, e.g. the Mississippi, Danube, Nile or Amur, the differences are small $(+/-5 \%)$. In South America, the seasonal water storage change calculated with CRU precipitation is generally greater than the values calculated with GPCC. Other basins with deviations in both directions are distributed inhomogeneously on a global scale. Precipitation correction (not shown) leads to an increase in seasonal $\triangle T W S$ especially in snow-dominated basins in northern Asia or North America because of higher correction factors in winter than in summer months, thus increasing the seasonal amplitude.

\subsection{Comparison with GRACE}

In order to compare WGHM results with GRACE, the hydrological model output and GRACE data have to be processed in the same way. Therefore, a spatial filtering technique us- ing a Gaussian-type filter with an averaging radius of 500 $\mathrm{km}$ is applied (see Schmidt et al., 2006 for details). Monthly storage variations are computed with WGHM for the years 2002-2005 and compared with results from GRACE for the Amazon basin (Fig. 3). For the year 2002, a strong influence of different precipitation input on WGHM calculations can be identified. Averaged over the whole Amazon basin, CRU precipitation is only $8 \%$ larger than GPCC but the intra-annual variability is more pronounced. That's why the CRU precipitation leads to larger monthly amplitudes of storage change than the GPCC data $(+33 \%)$. For the years 2003-2005, GRACE data show much larger amplitudes than WGHM model results in the Amazon basin. Those differences are larger than what could be expected from climate input uncertainties as evaluated for 2002.

Different precipitation input does not lead to significant differences in water storage change in all of the selected basins (as already mentioned in 3.3). But, in agreement with other comparison studies, the hydrological model shows generally smaller amplitudes of water storage change than GRACE. A comparison between GRACE and WGHM was also carried out by Schmidt et al. (2006). They found similar spatial patterns but also less temporal storage variations for WGHM. Ramillien et al. (2005) found a good spatial correlation between GRACE and WGHM but also differences in amplitude.

\section{Conclusions and outlook}

There are significant differences between the two global observation based precipitation data sets (CRU and GPCC). Continental water storage as calculated with the global 


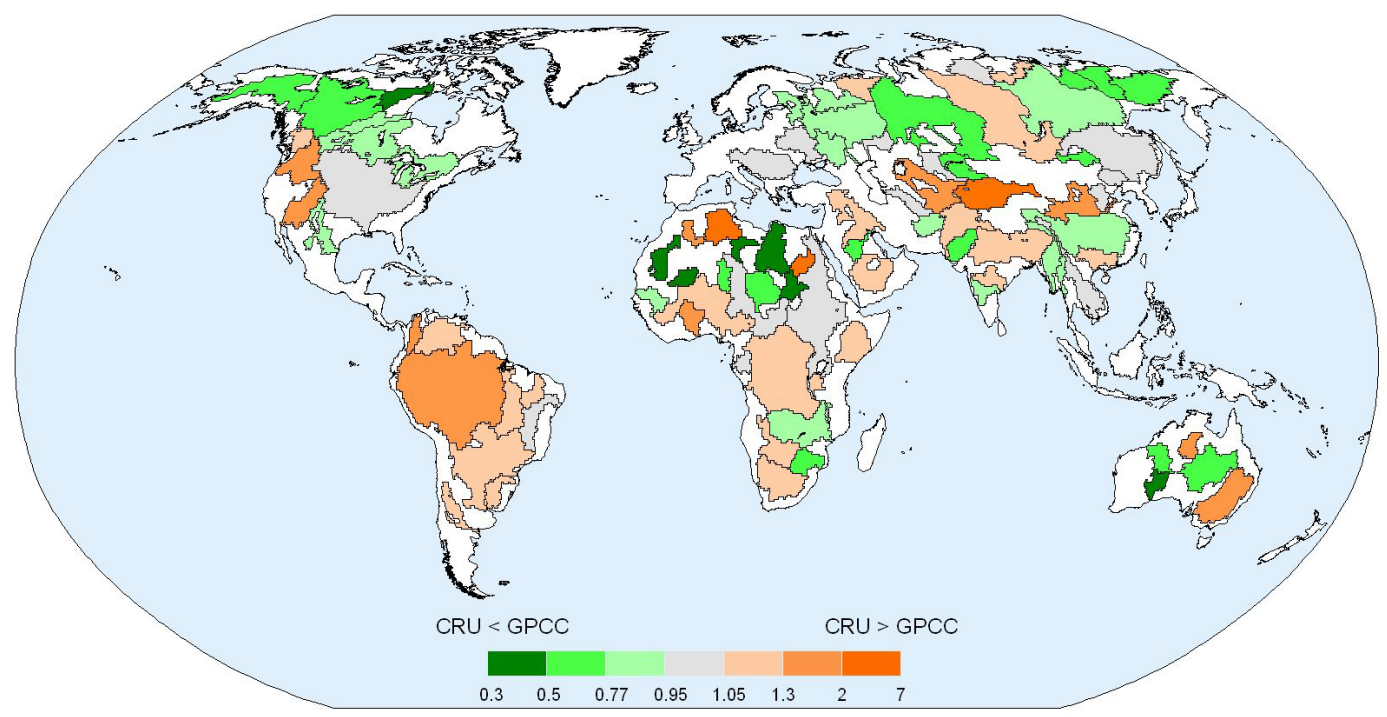

Fig. 2. Difference between seasonal water storage change for basins $>200000 \mathrm{~km}^{2}$ for the year 2002 calculated with WGHM based on CRU and GPCC precipitation data (ratio CRU/GPCC).

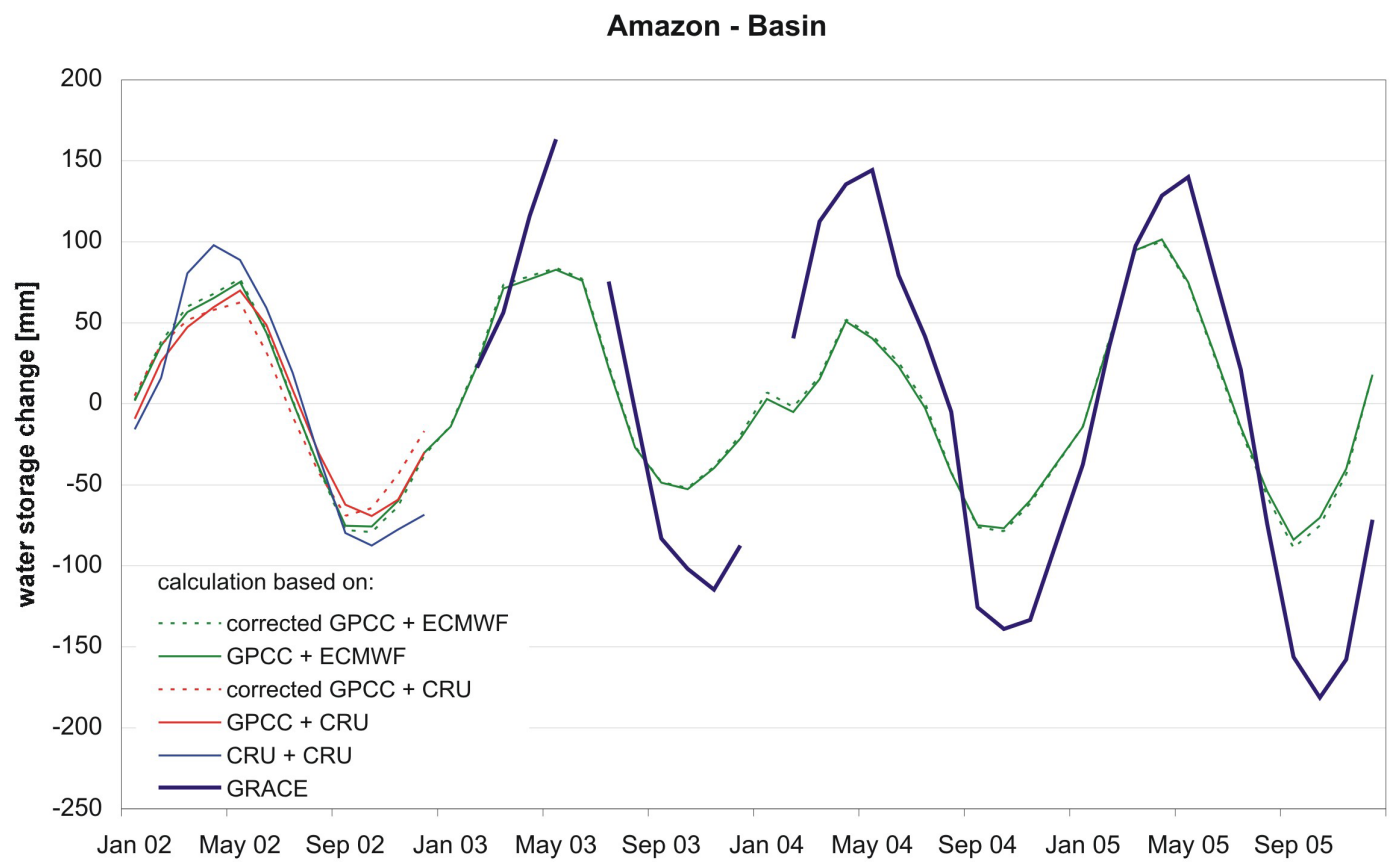

Fig. 3. Monthly water storage variations from GRACE and WGHM for the Amazon basin (2002-2005), calculations based on different climate data sets (legend: precipitation + other climate input, for details see Sect. 2).

hydrological model WGHM is highly sensitive to precipitation input. As a first preliminary result, precipitation correction leads to an increase in seasonal water storage change especially in northern snow-dominated basins. GRACE data tend to show higher seasonal amplitudes of continental water mass variations than WGHM in most river basins. This can only partially be explained by different precipitation data sets.
A more extended analysis of available climate data sets and their influence on water storage change computed with WGHM will be done in the future, including a more detailed sensitivity analysis. In addition, the role of individual storage components (contributing to total water storage with different proportions and phase) will be investigated. The relation between river discharge and water storage also has to be evaluated in order to improve the calibration strategy. A new 
promising approach to calibrate WGHM both with measured discharge and GRACE data is currently pursued at GFZ Potsdam. Finally, the total WGHM model uncertainty (climate input plus parameters and model structure) and GRACE uncertainty need to be assessed in order to quantify the reliability of both data sets.

The larger amplitudes of the GRACE signal might be an indicator that there are limitations of the hydrological model to account for all elements of continental water storage appropriately. However, GRACE results are also subject to a constant improvement of the data processing strategy by using improved background models for the separation of timevarying signals and by advanced de-aliasing methods.

Acknowledgements. The authors thank S. Werth and A. Güntner from GFZ Potsdam for providing meteorological input data and for post processing of WGHM output.

Edited by: K.-E. Lindenschmidt

Reviewed by: two anonymous referees

\section{References}

Adam, J. C. and Lettenmaier, D. P.: Adjustment of global gridded precipitation for systematic bias, J. Geophys. Res.-Atmos., 108(D9), 4257, doi:10.1029/2002JD002499, 2003.

Bergström, S.: The HBV Model - its structure and applications, SMHI Reports Hydrology, No. 4, 1992.

Döll, P., Kaspar, F., and Lehner, B.: A global hydrological model for deriving water availability indicators: model tuning and validation, J. Hydrol., 270(1-2), 105-134, 2003.

Hirschi, M., Seneviratne, S. I., and Schär, C.: Seasonal variations in terrestrial water storage for major midlatitude river basins, J. Hydrometeorol., 7(1), 39-60, 2006 a.

Hirschi, M., Viterbo, P., and Seneviratne, S. I.: Basin-scale waterbalance estimates of terrestrial water storage variations from ECMWF operational forecast analysis, Geophys. Res. Lett., 33(21), L21401, doi:10.1029/2006GL027659, 2006b.

Legates, D. R. and Willmott, C. J.: Mean Seasonal and Spatial Variability in Gauge-Corrected, Global Precipitation, Int. J. Climatol., 10(2), 111-127, 1990.
Mitchell, T. D. and Jones, P. D.: An improved method of constructing a database of monthly climate observations and associated high-resolution grids, Int. J. Climatol., 25(6), 693-712, 2005.

Nash, J. E. and Sutcliffe, J. V.: River flow forecasting through conceptual models part I - A discussion of principles, J. Hydrol., 10(3), 282-290, 1970.

New, M., Lister, D., Hulme, M., and Makin, I.: A high-resolution data set of surface climate over global land areas, Clim. Res., 21(1), 1-25, 2002.

Österle, H., Gerstengarbe, F.-W., and Werner, P. C.: Homogenisierung und Aktualisierung des Klimadatensatzes der Climate Research Unit der University of East Anglia, Norwich, Terra Nostra 6. Deutsche Klimatagung, 326-329, 2003.

Ramillien, G., Cazenave, A., and Brunau, O.: Global time variations of hydrological signals from GRACE satellite gravimetry, Geophys. J. Int., 158(3), 813-826, 2004.

Ramillien, G., Frappart, F., Cazenave, A., and Güntner, A.: Time variations of land water storage from an inversion of 2 years of GRACE geoids, Earth Planet. Sci. Lett., 235(1-2), 283-301, 2005.

Rodell, M. and Famiglietti, J. S.: An analysis of terrestrial water storage variations in Illinois with implications for the Gravity Recovery and Climate Experiment (GRACE), Water Resour. Res. 37(5), 1327-1339, 2001.

Rodell, M. and Famiglietti, J. S.: The potential for satellite-based monitoring of groundwater storage changes using GRACE: the High Plains aquifer, Central US, J. Hydrol., 263(1-4), 245-256, 2002.

Rudolf, B. and Schneider, U.: Calculation of gridded precipitation data for the global land-surface using in-situ gauge observations, 2nd Workshop of the International Precipitation Working Group, 1-17, 2005.

Schmidt, R., Schwintzer, P., Flechtner, F., Reigber, Ch., Güntner, A., Döll, P., Ramilien, G., Cazenave, A., Petrovic, S., Jochmann, H., and Wünsch, J.: GRACE observations of changes in continental water storage, Global Planet. Change, 50(1-2), 112-126, 2006.

Seneviratne, S. I., Viterbo, P., Lüthi, D., and Schär, C.: Inferring changes in terrestrial water storage using ERA-40 reanalysis data: The Mississippi River basin, J. Climate, 17(11), 2039 2057, 2004. 